\title{
RESÍDUO DA SEMENTE DE URUCUM (Bixa orellana L.) COMO CORANTE DA GEMA, PELE, BICO E OVÁRIO DE POEDEIRAS AVALIADO POR DOIS MÉTODOS ANALÍTICOS
}

\author{
Evaluating of annatto (Bixa orellana L.) seeds by-product as yolk, skin, beak and ovary \\ coloring of hens using two analytical methods
}

\author{
José Humberto Vilar da Silva ${ }^{1}$, Edson Lindolfo da Silva², José Jordão Filho ${ }^{3}$, \\ Marcelo Luís Gomes Ribeiro ${ }^{3}$, Fernando Guilherme Perazzo Costa ${ }^{4}$
}

\begin{abstract}
RESUMO
O experimento foi realizado com o objetivo de avaliar o resíduo da semente de urucum (RSU) como ingrediente e aditivo corante de diferentes tecidos de 125 poedeiras Lohmann-LSL, com 22 semanas de idade e 1,65 kg de peso vivo, distribuídas num delineamento inteiramente ao acaso em cinco tratamentos com cinco repetições de cinco aves. $\mathrm{O}$ tratamento $1\left(\mathrm{~T}_{1}\right)=$ ração à base de milho+farelo de soja (M+FS); $\mathrm{T}_{2}=$ ração à base de sorgo $(40 \%)+\mathrm{FS} ; \mathrm{T}_{3}=\mathrm{T}_{2}+4 \%$ RSU; $\mathrm{T}_{4}=\mathrm{T}_{2}+8 \%$ RSU e $\mathrm{T}_{5}=\mathrm{T}_{2}+12 \%$ RSU. Foram fornecidos $110 \mathrm{~g}$ de ração/ave/dia e água à vontade. As coletas foram realizadas em três períodos de 28 dias. A pigmentação dos diferentes tecidos foi avaliada pelo método $1\left(\mathrm{M}_{1}\right)$ do leque colorimétrico da Roche® e, pelo método $2\left(\mathrm{M}_{2}\right)$ do escore "b+", que mede a cor amarela, pelo cromatográfo Minolta ${ }^{\circledR}$ CR-10. Excetuando-se os $\mathrm{T}_{1}$ e $\mathrm{T}_{2}$ da análise de variância, o aumento do RSU na ração com $40 \%$ de sorgo melhorou, linearmente, o consumo, produção, massa, conversão alimentar por massa e por dúzia de ovos. A pigmentação da gema analisada pelos $M_{1}$ e $M_{2}$, do bico pelo $M_{2}$ e do ovário pelo $M_{1}$ melhoraram com o aumento do RSU. Alta correlação ( $r=0,72$; $\mathrm{P}<0,001)$ foi detectada entre o $\mathrm{M}_{1}$ e $\mathrm{M}_{2}$ para pigmentação da gema. Recomenda-se até $12 \%$ de RSU em rações contendo sorgo como principal fonte de energia para melhorar a pigmentação da gema e a produção de ovos.
\end{abstract}

Termos para indexação: Aditivo, alimento alternativo, produção de ovos, sorgo, pigmentante, urucum, Bixa orellana.

\begin{abstract}
A experiment was carried out in the Poultry Science Station of CFT/UFPB with the objective to evalluate the annatto seeds bran (ASB) as an ingredient and as an additive colouring of several tissue in 125 hens Lohmann LSL with twenty-two weeks of age, $1.65 \mathrm{~kg}$ of live weight, allocated in the completely randomized design, with five treatments and five replication of five hens. The treatment $1\left(\mathrm{~T}_{1}\right)=$ diet based on corn and soybean meal; $\mathrm{T}_{2}=\operatorname{diet}+40 \%$ of sorghum; $\mathrm{T}_{3}=\mathrm{T}_{2}+4 \%$ ASB; $\mathrm{T}_{4}=\mathrm{T}_{2}+8 \%$ ASB; e $\mathrm{T}_{5}=\mathrm{T}_{2}+12 \% \mathrm{ASB}$. The birds were fed $110 \mathrm{~g}$ of diet/day and water ad libitum. The collect were obtained in three periods of twentyeight days. Collor changes were measured with yolk the Roche ${ }^{\circledR}$ collor fan method $\left(M_{1}\right)$ and score calculated from " $b+$ " (yellowness) of Minolta ${ }^{\circledR}$ CR-10 instrument $\left(\mathrm{M}_{2}\right)$. Excepting the $\mathrm{T}_{1}$ and $\mathrm{T}_{2}$ of analysis of variance, the increase of ASB in diet with $40 \%$ of sorghum improved, linearly, intake, egg production, egg mass, egg mass and egg dozen feed conversion ratio. The yolk color by $\mathrm{M}_{1}$ and $\mathrm{M}_{2}$, beak by $\mathrm{M}_{2}$ and ovary by $\mathrm{M}_{1}$ improved with the increasing of ASB in diets. A high correlation coefficient $(\mathrm{r}=0.72 ; \mathrm{P}<0.001)$ was observed for yolk collor among $\mathrm{M}_{1}$ and $\mathrm{M}_{2}$. Suggested up to $12 \%$ of ASB in diet where sorghum is principal source of energy to improve yolk pigmentation and egg production.
\end{abstract}

Index terms: Additive, alternative feedstuffs, egg production, read pigmentant sorghum, annatto, Bixa orellana.

(Recebido para publicação em 9 de março de 2006 e aprovado em 11 de julho de 2006)

\section{INTRODUÇÃO}

A ração responde por cerca de $65 \%$ do custo de produção de poedeiras e, o milho e o farelo de soja constituem em torno de $92 \%$ das rações e $88 \%$ do seu custo. Muitos estudos têm sido realizados no Brasil e no mundo visando a substituição do milho, do farelo de soja, e de sua mistura, por alimentos mais baratos e de fácil disponibilidade regional.

Segundo Silva et al. (2000), o sorgo pode substituir o milho em rações de poedeiras, mas é preciso fazer a inclusão de fontes de pigmentantes para compensar a perda de coloração da gema dos ovos causada pela baixa concentração de pigmentos no sorgo. O uso de pigmentantes artificiais tem sido alvo de questionamentos na Europa e no mundo, enquanto os pigmentantes naturais apesar de não enfrentarem restrições de uso, apresentam alto preço de aquisição. A solução para o uso de sorgo em larga escala na ração de poedeiras depende da identificação de novas fontes de pigmentos naturais de baixo custo.

O resíduo agroindustrial da semente de urucum é um subproduto da extração agroindustrial da bixina que

${ }_{1}^{1}$ Professor do DAP/CFT/UFPB/Campus III - 58.220-000 - Bananeiras, PB - Bolsista PQ-CNPq - jvilar@cft.ufpb.br

${ }^{2}$ Aluno do Doutorado em Zootecnia - Departamento de Zootecnia/DZO - Universidade Federal de Lavras/UFLA - Cx.P. 3037 - 37.200-000 - Lavras, MG Bolsista CNPq - edsonlindolfo@yahoo.com.br

${ }^{3}$ Aluno de Doutorado Integrado em Zootecnia - PDIZ - UFPB/UFC/UFRPE - 58.397-000 - Areia, PB - Bolsista CAPES - marcelo@cft.ufpb.br

${ }^{4}$ Professor do DZO/CCA - Universidade Federal da Paraíba/UFPB - Campus II - 58.397-000 - Areia, PB - Bolsista PQ-CNPq - fperazzo@cca.ufpb.br 
por apresentar forte coloração vermelha e uma camada externa de óleo de soja, usado como veículo para diluição da bixina, tem despertado a atenção como aditivo pigmentante da gema de ovos. O aumento da escala de extração agroindustrial da bixina resulta em 94 a $98 \%$ de sobras, que ao serem descartadas pela indústria, pode poluir o meio ambiente.

Vários estudos têm testado o extrato oleoso de bixina como corante da gema dos ovos (SILVA et al., 2000) e da pele de frangos de corte (PEREIRA et al., 2001), assim como, o aproveitamento da farinha integral da semente de urucum nos níveis de 3\% (SQUIBB et al., 1953), 2\% (CAMPOS, 1955) e 0,1 a 0,6\% (ARRAYA et al., 1977).

Apesar de Arraya et al. (1977) terem afirmado que o baixo teor e a reduzida utilização dos pigmentos, além do alto conteúdo em fibra bruta, limitarem o uso deste subproduto na ração de aves, um estudo determinou a viabilidade de sua inclusão em até $10 \%$ na ração de frangos de corte de 1 a 47 dias de idade (SILVA et al., 2005). Entretanto, nenhum trabalho foi realizado para avaliar o potencial de uso deste subproduto como corante da gema e ingrediente de rações de poedeiras comerciais. $\mathrm{O}$ trabalho foi realizado tendo como objetivo avaliar o nível de inclusão e o potencial do resíduo da semente de urucum (Bixa orellana L.) como pigmentante da gema dos ovos de poedeiras alimentadas com rações contendo sorgo como principal fonte energética.

\section{MATERIAL E MÉTODOS}

O experimento foi desenvolvido no Setor de Pesquisas em Nutrição de Aves - SPNA, do Centro de Formação de Tecnólogos, Campus III da UFPB na cidade de Bananeiras-PB. Foram utilizadas 125 poedeiras da Linhagem Lohmann LSL, alojadas com 22 semanas de idade e peso médio de $1,65 \mathrm{~kg}$.

Inicialmente, as aves foram selecionadas pelo peso vivo e, após duas semanas de alimentação com uma dieta única, foram submetidas a uma nova seleção com base na produção de ovos. Posteriormente, foram alimentadas com as dietas experimentais durante uma semana, antes do início dos períodos de coletas. O galpão experimental apresentava pé direito de $1,8 \mathrm{~m}$, largura de $4 \mathrm{~m} \mathrm{e}$ comprimento de $26 \mathrm{~m}$, cobertura de telhas de barro em duas águas e duas fileiras duplas de gaiolas de arame galvanizado, $0,25 \times 0,45 \times 0,33 \mathrm{~m}$, separadas por um corredor central de $0,8 \mathrm{~m}$, sendo aberto nas laterais.

Uma ração controle, à base de milho e de farelo de soja, e outra, tendo o sorgo como principal fonte de energia (Tabela 1), foram formuladas de acordo com as recomendações de Rostagno et al. (2000), sendo a última suplementada com $0,4,8$ e $12 \%$ do resíduo da semente de urucum (RSU). As rações foram isonutritivas para todos os nutrientes.

$\mathrm{O}$ experimento foi realizado num delineamento inteiramente ao acaso com cinco repetições de cinco aves. As amostras foram colhidas durante três períodos de 28 dias de duração. Ao final de cada período, as sobras de rações dos comedouros e dos baldes foram pesadas e o consumo de ração foi mensurado. A produção (ave/dia), o peso médio (g/ave/dia), a massa (g/ave/dia) e as conversões alimentares por massa $(\mathrm{kg} / \mathrm{kg})$ e por dúzia de ovos $(\mathrm{kg} / \mathrm{dz})$ foram obtidas em cada período experimental.

No final do experimento, foram abatidas duas aves de cada parcela experimental, após um jejum de oito horas, para realizar as medições de pigmentação do ovário e dos pesos e rendimentos de vísceras e de orgãos em relação ao peso vivo das aves. Foram pesados e calculados os percentuais do trato gastrointestinal total (do início do esôfago superior até a cloaca), fígado, pâncreas e coração.

A pigmentação da porção superior do bico e da parte anterior da canela das aves foi medida utilizando o aparelho cromatógrafo Minolta ${ }^{\circledR}$ CR-10, que expressa as cores através dos escores L que mensura a luminosidade variando de zero (preto) a 100 (branco), a+ (até 100) correspondendo ao vermelho e a- (até -80) ao verde, e b+ (até 70) correspondendo a cor amarela e b- (até-100) a cor azul. Também, foram avaliadas, concomitantemente, pelo cromatógrafo Minolta ${ }^{\circledR}$ e o leque colorimétrico da Roche $\AA$ as pigmentações da gema e dos três maiores folículos do ovário. No uso do aparelho Minolta ${ }^{\circledR}$, foram obtidas médias de três medições por cada tecido avaliado, e optou-se pelo escore "b+", em virtude de representar a cor amarela.

A análise de variância dos dados foi realizada pelo programa SAEG desenvolvido pela Universidade Federal de Viçosa - UFV (1983) e as médias das variáveis foram comparadas pelo teste Student Newman Keuls $(\mathrm{P} \leq 0,05)$. As análises de regressão foram realizadas, excluindo-se os tratamentos 1 e 2, que não continham o resíduo da semente de urucum, e a escolha do modelo de regressão considerou o nível de significancia $(\mathrm{P} \leq 0,05)$, o coeficiente de determinação do modelo $\left(\mathrm{R}^{2}\right)$ e a resposta biológica das aves.

\section{RESULTADOS E DISCUSSÃO}

Considerando o resultado do teste de média, o consumo de ração foi maior no tratamento em que a ração foi formulada à base de milho e de farelo de soja em relação ao tratamento com $40 \%$ de sorgo sem inclusão do RSU ( $\mathrm{P} \leq 0,01)$, mas nenhuma diferença foi constatada quando a ração contendo $40 \%$ de sorgo foi suplementada com até $12 \%$ de RSU (Tabela 2). 
TABELA 1 - Composição das rações experimentais em ingredientes e valores nutricionais.

\begin{tabular}{|c|c|c|c|c|c|}
\hline \multirow[b]{2}{*}{ Ingredientes } & \multicolumn{5}{|c|}{ Tratamentos $^{1}$} \\
\hline & DB & $40 \% \mathrm{~S}+0 \% \mathrm{RSU}$ & $40 \% \mathrm{~S}+4 \% \mathrm{RSU}$ & $40 \% \mathrm{~S}+8 \% \mathrm{RSU}$ & $40 \% \mathrm{~S}+12 \% \mathrm{RSU}$ \\
\hline Milho $-8,8 \%$ PB & 65,234 & 23,866 & 19,239 & 14,612 & 9,985 \\
\hline Farelo de soja $-45 \%$ PB & 22,439 & 22,432 & 22,171 & 21,910 & 21,649 \\
\hline Sorgo de baixo tanino - $11 \%$ PB & 0,000 & 40,000 & 40,000 & 40,000 & 40,000 \\
\hline RSU $-12,1 \%$ PB & 0,000 & 0,000 & 4,000 & 8,000 & 12,000 \\
\hline Calcário & 9,253 & 9,254 & 9,245 & 9,236 & 9,227 \\
\hline Fosfato bicálcico & 1,514 & 1,499 & 1,522 & 1,544 & 1,567 \\
\hline DL-metionina - $99 \%$ & 0,151 & 0,174 & 0,192 & 0,210 & 0,229 \\
\hline L-lisina $\mathrm{HCl}-78,4 \%$ & 0,002 & 0,018 & 0,039 & 0,059 & 0,080 \\
\hline Óleo de soja & 0,567 & 1,908 & 2,740 & 3,571 & 4,402 \\
\hline Sal comum & 0,480 & 0,489 & 0,492 & 0,498 & 0,501 \\
\hline Premix vitamínico ${ }^{2}$ & 0,100 & 0,100 & 0,100 & 0,100 & 0,100 \\
\hline Premix mineral $^{3}$ & 0,100 & 0,100 & 0,100 & 0,100 & 0,100 \\
\hline Cloreto de colina $-70 \%$ & 0,150 & 0,150 & 0,150 & 0,150 & 0,150 \\
\hline Antioxidante $^{4}$ & 0,010 & 0,010 & 0,010 & 0,010 & 0,010 \\
\hline Total & 100,000 & 100,000 & 100,000 & 100,000 & 100,000 \\
\hline \multicolumn{6}{|l|}{ Composição química } \\
\hline $\mathrm{PB}, \%$ & 15,900 & 15,900 & 15,900 & 15,900 & 15,900 \\
\hline EM, kcal & 2.800 & 2.800 & 2.800 & 2.800 & 2.800 \\
\hline Cálcio & 4,020 & 4,020 & 4,020 & 4,020 & 4,020 \\
\hline Fósforo disponível & 0,375 & 0,375 & 0,375 & 0,375 & 0,375 \\
\hline Met+Cis & 0,676 & 0,677 & 0,675 & 0,673 & 0,670 \\
\hline Lisina & 0,789 & 0,785 & 0,783 & 0,780 & 0,778 \\
\hline Treonina & 0,615 & 0,610 & 0,590 & 0,570 & 0,550 \\
\hline Triptofano & 0,185 & 0,196 & 0,192 & 0,187 & 0,183 \\
\hline
\end{tabular}

${ }^{1} \mathrm{DB}=$ dieta basal; $\mathrm{S}=$ sorgo e, $\mathrm{RSU}=$ resíduo da semente de urucum.

${ }^{2}$ Composição básica do produto (composition basic of product): Vitamina $\mathrm{A}$, vitamina $\mathrm{D}_{3}$, vitamina $\mathrm{E}$, vitamina $\mathrm{K}$, vitamina $\mathrm{B}_{1}$, vitamina $\mathrm{B}_{2}$, vitamina $\mathrm{B}_{6}$, vitamina $\mathrm{B}_{12}$, Niacina, Ácido Fólico, Ácido Pantotênico, Selenito de Sódio, Aditivo Antioxidante, Veiculo Q.S.P. Níveis de garantia por kg do produto (Level security per $\mathrm{kg}$ of product): Vitamina A 10.000.000 U.I, Vitamina $D_{3} 2.500 .000$ U.I, Vitamina E 6.000 U.I, Vitamina K $1.600 \mathrm{mg}$, Vitamina $\mathrm{B}_{12} 11.000 \mathrm{mg}$, Niacina 25.000 mg, Ácido Fólico 400 mg, Ácido Pantotênico 10.000 mg, Selênio 300 mg, Antioxidante 20 g.

${ }^{3}$ Composição básica do produto (composition basic of product): Monóxido de manganês, óxido de zinco, sulfato de ferro, sulfato de cobre, iodeto de cálcio, veículo Q.S.P. Níveis de garantia por $\mathrm{kg}$ do produto (Level security per $\mathrm{kg}$ of product): Manganês $150.000 \mathrm{mg}$, Zinco $100.000 \mathrm{mg}$, Ferro $100.000 \mathrm{mg}$, Cobre $16.000 \mathrm{mg}$, Iodo $1.500 \mathrm{mg}$.

${ }^{4}$ Butil Hidroxi Tolueno.

A produção de ovos foi maior $(\mathrm{P} \leq 0,05)$ no tratamento contendo $40 \%$ de sorgo e $12 \%$ de RSU em relação aos tratamentos com $40 \%$ de sorgo e 4 ou $8 \%$ de RSU, entretanto, a produção de ovos das aves recebendo a ração à base de milho e farelo de soja não diferiu dos outros tratamentos $(\mathrm{P}>0,05)$, enquanto, o peso e a massa de ovos não foram afetados $(\mathrm{P}>0,05)$.
Excluindo-se os tratamentos 1 e 2 da análise de variância, pela ausência de RSU nas rações, observou-se aumentos lineares no consumo de ração das aves $\left(\mathrm{Y}=108,630+0,538235 \mathrm{X} ; \mathrm{r}^{2}=0,78\right)$, produção de ovos $\left(\mathrm{Y}=70,9127+4,16667 \mathrm{X} ; \mathrm{r}^{2}=0,75\right)$ e na massa de ovos produzida $\left(Y=45,2510+2,84547 \mathrm{X} ; \mathrm{r}^{2}=0,83\right)$ decorrente do aumento da inclusão do RSU na ração.

Ciênc. agrotec., Lavras, v. 30, n. 5, p. 988-994, set./out.., 2006 
TABELA 2 - Efeito da ração formulada à base de milho e farelo de soja (M+FS) e das rações contendo sorgo suplementadas com o resíduo da semente de urucum (RSU) sobre o consumo de ração $(\mathrm{CR})$, produção $(\mathrm{PR})$, peso $(\mathrm{PO})$ e massa de ovos (MO) e resultado da análise de variância (ANOVA) ${ }^{1}$.

\begin{tabular}{lcccc}
\hline \multicolumn{1}{c}{ Tratamento } & $\begin{array}{c}\text { CR } \\
\text { (g/ave/dia) }\end{array}$ & $\begin{array}{c}\text { PR } \\
\text { (\%/ave/dia) }\end{array}$ & $\begin{array}{c}\text { PO } \\
\text { (g/ave/dia) }\end{array}$ & $\begin{array}{c}\text { MO } \\
\text { (g/ave/dia) }\end{array}$ \\
\hline Controle (M+FS) & $111,24^{\mathrm{a}}$ & $83,28^{\mathrm{ab}}$ & 65,15 & 54,26 \\
$40 \%$ Sorgo+0\%RSU & $107,98^{\mathrm{b}}$ & $78,88^{\mathrm{b}}$ & 66,36 & 52,34 \\
$40 \%$ Sorgo+4\%RSU & $109,87^{\mathrm{ab}}$ & $76,29^{\mathrm{b}}$ & 63,01 & 48,07 \\
$40 \%$ Sorgo+8\%RSU & $109,92^{\mathrm{ab}}$ & $79,68^{\mathrm{b}}$ & 64,87 & 51,69 \\
$40 \%$ Sorgo+12\%RSU & $110,95^{\mathrm{a}}$ & $87,93^{\mathrm{a}}$ & 64,55 & 56,76 \\
\hline ANOVA & & & & $\mathrm{ns}$ \\
\hline Tratamentos & $* *$ & $* *$ & $\mathrm{~ns}$ & $\mathrm{n}$ \\
$\mathrm{RSU}^{2}$ & $\mathrm{~L}^{*}$ & $\mathrm{~L}^{* *}$ & 3,81 & 6,21 \\
\hline $\mathrm{CV}(\%)$ & 1,15 & 3,20 & $\mathrm{~ns}$ & \\
\hline
\end{tabular}

${ }^{1}$ Médias seguidas de letras diferentes nas colunas, são estatisticamente distintas pelo teste SNK $(\mathrm{P} \leq 0,05)$.

${ }^{2}$ Efeitos linear $(\mathrm{L})$, em que: *(P $\left.\leq 0,05\right) ; * *(\mathrm{P} \leq 0,01)$.

Ns = não-significativo.

O aumento do consumo da ração com $40 \%$ de sorgo, à medida que o nível de RSU passou de 4 para $12 \%$, pode ter sido provocada pela maior coloração vermelha da ração, causando maior atração nas aves. Porém, nenhuma evidência corroborando esta hipótese foi encontrada na literatura. No trabalho de Silva et al. (2005), em que frangos de corte foram alimentados de 1 a 47 dias de idade com níveis crescentes do RSU na ração $(0 ; 2,5 ; 5 ; 7,5 ; 10 ; 12,5$ e $15 \%)$, não foi constatado efeito atrativo da tonalidade de pigmentação da ração sobre o consumo das aves.

Outro fator que pode ter contribuído para o aumento do consumo das rações com $40 \%$ de sorgo suplementadas em níveis crescentes do RSU foi o efeito de diluição da energia promovido pelo aumento da fibra da ração. Observou-se que o aumento do RSU reduziu a proporção de milho na dieta de 23,9 para $9,9 \%$, com possível elevação da fibra e redução do aproveitamento da energia, fazendo com que as aves, procurassem compensar o baixo aproveitamento energético, consumindo mais ração.

Miyada et al. (2002) recomendaram até $10 \%$ do RSU na ração de suínos em crescimento e, da mesma forma, Silva et al. (2005), também, sugeriram nível semelhante de inclusão deste subproduto na ração inicial, crescimento e final de frangos de corte.

Na Tabela 3 são apresentadas as conversões por massa e por dúzia de ovos e o peso específico. Pelo resultado do teste de média, a conversão alimentar por dúzia de ovos das aves alimentadas com a ração à base de milho e de farelo de soja não diferiu dos demais tratamentos, enquanto o tratamento com $12 \%$ do RSU proporcionou melhor conversão por dúzia de ovos que os tratamentos com 4 e $8 \%$ de RSU $(P \leq 0,05)$.

Excluindo-se os tratamentos que não continham o RSU da análise de variância, observou-se efeito linear $(\mathrm{P} \leq 0,05)$ sobre as conversões alimentares por massa $\left(\mathrm{Y}=2,37283-0,103897 \mathrm{X} ; \mathrm{r}^{2}=0,89\right)$ e por dúzia de ovos $\left(\mathrm{Y}=1,80601-0,07150355 ; \mathrm{r}^{2}=0,77\right)$, melhorando à medida que o nível do subproduto passou de 4 para $12 \%$ na ração.

Trabalhando com frangos de corte, Silva et al. (2005) não constataram nenhum efeito negativo do aumento do nível de farelo de resíduo de urucum na ração de 2,5 para $15 \%$ nas fases de 1 a 21; 22 a $42 ; 43$ a 47 e no período total de 1 a 47 dias.

$\mathrm{Na}$ Tabela 4 são apresentados os resultados das avaliações de coloração do bico, canela, ovário e gema pelo leque colorimétrico da Roche ${ }^{\circledR}$ e o escore "b+" do aparelho cromatógrafo Minolta ${ }^{\circledR}$.

As avaliações da coloração da gema pelo leque e pelo aparelho Minolta ${ }^{\circledR}$ indicaram que a melhor pigmentação da gema foi obtida com a ração contendo milho e farelo de soja $(\mathrm{P}<0,05)$, enquanto o pior resultado foi observado com a ração com $40 \%$ de sorgo. A suplementação da mesma com 4; 8 e $12 \%$ de RSU, melhorou a pigmentação da gema, mas foi insuficiente para oferecer resultado semelhante ao da dieta à base de milho e farelo de soja.

Excluindo-se os tratamentos 1 e 2 da análise de variância, por não conterem o RSU nas rações, constatou-se que a pigmentação do bico das aves, medida através do escore "b+" do aparelho Minolta ${ }^{\circledR}$, cresceu linearmente $(\mathrm{P}<0,05)$, quando o RSU passou de 4 para $12 \%$ na ração contendo $40 \%$ de sorgo $\left(Y=-0,581778+1,18450 X ; r^{2}=0,96\right)$. 
TABELA 3 - Efeito da ração formulada à base de milho e de farelo de soja (M+FS) e das rações contendo sorgo suplementadas com o resíduo da semente de urucum (RSU) sobre as conversões alimentares por massa e por dúzia de ovos, gravidade específica e o resultado da análise de variância (ANOVA).

\begin{tabular}{lccc}
\hline \multicolumn{1}{c}{ Tratamentos } & $\begin{array}{c}\text { Conversão por massa } \\
(\mathbf{k g} / \mathbf{k g})\end{array}$ & $\begin{array}{c}\text { Conversão por dúzia } \\
(\mathbf{k g} / \mathbf{d z})\end{array}$ & Peso específico \\
\hline Controle (M+FS) & 2,050 & $1,576^{\mathrm{ab}}$ & 1,090 \\
$40 \%$ Sorgo+0\%RSU & 2,063 & $1,570^{\mathrm{ab}}$ & 1,090 \\
$40 \%$ Sorgo+4\%RSU & 2,286 & $1,640^{\mathrm{a}}$ & 1,081 \\
$40 \%$ Sorgo+8\%RSU & 2,126 & $1,635^{\mathrm{a}}$ & 1,090 \\
$40 \%$ Sorgo+12\%RSU & 1,955 & $1,497^{\mathrm{b}}$ & 1,089 \\
\hline ANOVA & & & $\mathrm{ns}$ \\
\hline Tratamentos & $\mathrm{ns}$ & $*$ & $\mathrm{~ns}$ \\
\hline $\mathrm{RSU}^{1}$ & $\mathrm{~L} *$ & $\mathrm{~L}^{*}$ & 1,15 \\
\hline $\mathrm{CV}(\%)$ & 6,17 & 4,05 & \\
\hline
\end{tabular}

a,b,c Médias seguidas de letras distintas são diferentes pelo teste SNK (P d” 0,05).

${ }^{1}$ Efeitos linear (L), em que: $*(\mathrm{P}<0,05)$.

$\mathrm{Ns}=$ não-significativo

TABELA 4 - Pigmentação de tecidos medida pelo aparelho Minolta e o leque colorimétrico da Roche em função da ração à base de milho e de farelo de soja (M+FS) e da ração contendo $40 \%$ de sorgo suplementada com o resíduo da semente de urucum (RSU).

\begin{tabular}{|c|c|c|c|c|c|c|}
\hline \multirow{2}{*}{ Tratamentos } & \multicolumn{4}{|c|}{ Aparelho Minolta } & \multicolumn{2}{|c|}{ Leque Roche ${ }^{\circledR}$} \\
\hline & Bico & Canela & Ovário & Gema & Ovário & Gema \\
\hline Controle (M+FS) & 17,12 & 16,08 & $32,13^{\mathrm{a}}$ & $39,29^{\mathrm{a}}$ & $8,20^{\mathrm{a}}$ & $6,60^{\mathrm{a}}$ \\
\hline $40 \%$ Sorgo $+0 \%$ RSU & 3,65 & 14,55 & $23,37^{\mathrm{b}}$ & $26,48^{\mathrm{c}}$ & $5,00^{\mathrm{b}}$ & $1,93^{\mathrm{c}}$ \\
\hline $40 \%$ Sorgo $+4 \%$ RSU & 3,59 & 14,23 & $24,46^{\mathrm{b}}$ & $27,02^{\mathrm{c}}$ & $6,07^{\mathrm{b}}$ & $3,67^{\mathrm{b}}$ \\
\hline $40 \%$ Sorgo $+8 \%$ RSU & 10,02 & 15,64 & $26,87^{\mathrm{b}}$ & $30,50^{\mathrm{b}}$ & $8,13^{\mathrm{a}}$ & $4,46^{\mathrm{b}}$ \\
\hline $40 \%$ Sorgo $+12 \%$ RSU & 13,06 & 15,80 & $25,40^{\mathrm{b}}$ & $31,78^{\mathrm{b}}$ & $8,27^{\mathrm{a}}$ & $4,73^{\mathrm{b}}$ \\
\hline \multicolumn{7}{|l|}{ ANOVA } \\
\hline Tratamentos & $* *$ & ns & $* *$ & ns & $* *$ & $* *$ \\
\hline $\mathrm{RSU}^{1}$ & $\mathrm{~L}^{* *}$ & $\mathrm{~ns}$ & $* *$ & $\mathrm{~L}^{* *}$ & $\mathrm{~L}^{* *}$ & $\mathrm{~L}^{* *}$ \\
\hline$\% \mathrm{CV}$ & 22,12 & 23,32 & 7,81 & 5,58 & 11,69 & 8,01 \\
\hline
\end{tabular}

a,b,c Médias seguidas de letras distintas são diferentes pelo teste SNK (P d" 0,05).

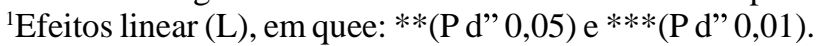

Ns = não-significativo.

Por outro lado, foi constatada alta correlação positiva entre a análise da pigmentação da gema realizada pelo leque colorimétrico e pelo escore " $\mathrm{b}+$ " do aparelho Minolta $(r=0,72 ; P<0,001)$, entretanto a correlação entre as pigmentações do ovário obtidas com as duas metodologias foi menos expressiva $(r=0,5178 ; \mathrm{P}<0,004)$.
Também, baixas correlações foram detectadas entre a pigmentação do bico medida pelo escore " $b+$ " com o resultado da pigmentação do ovário pelo leque colorimétrico $(r=0,2153 ; P>0,05)$ e a pigmentação da gema avaliada pelo leque $(\mathrm{r}=0,3050 ; \mathrm{P}<0,06)$, no entanto a correlação constatada entre a pigmentação do bico 
determinada pelo escore "b+" do aparelho Minolta com a coloração da gema medida pelo mesmo aparelho foi mais alta $(\mathrm{r}=0,555 ; \mathrm{P}<0,002)$.

A coloração da porção superior do bico como indicador do grau de pigmentação da gema dos ovos tem as vantagens da rapidez nas respostas e do método não ser invasivo nem destrutivo do ovo como o leque colorimétrico. Entretanto, as correlações da cor do bico com a gema não foram significativas e novos estudos deverão ser realizados para avaliar a acurácia e a repetibilidade deste método na detecção de possíveis alterações na cor da gema associadas a mudanças na coloração do bico das aves.

Considerando, novamente, apenas as rações com $40 \%$ de sorgo, verificou-se que o escore de pigmentação da gema pelo leque $(Y=3,22222+$ $\left.0,13333 X ; r^{2}=0,92\right)$, e pelo escore " $b+$ " $(Y=25,2086+$ $\left.0,557500 X ; r^{2}=0,91\right)$, cresceu linearmente $(P<0,05)$ com o aumento do RSU na ração (Tabela 4). Resultado semelhante foi observado por Arraya et al. (1977) trabalhando com uma ração contendo $66 \%$ de sorgo suplementada com 0,1 a $0,6 \%$ de semente integral de urucum. Para obter gemas com escore 9 pelo leque colorimétrico, semelhante ao ovo caipira (SILVA et al., 2000), é necessário incluir cerca de 43,33\% de RSU numa ração com $40 \%$ de sorgo. Entretanto, níveis elevados de RSU, provavelmente, deverão limitar o desempenho das aves pelo aumento da fibra na ração.
Valor de $1,06 \%$ de inclusão da farinha integral da semente de urucum para obter gemas com escore semelhante aquele de aves caipiras foi estimado por Arraya et al. (1977), numa ração com 66\% de sorgo.

A avaliação da pigmentação dos três maiores folículos presente no ovário das aves pelo leque colorimétrico, resultou em aumento linear da cor amarela $(\mathrm{P}$ $<0,05)$ à medida que o RSU passou de 4 para $12 \%$ na ração $\left(\mathrm{Y}=5,28889+0,275000 \mathrm{X} ; \mathrm{r}^{2}=0,80\right)$, mas nenhum efeito foi constatado pelo escore "b+" do aparelho Minolta® $(\mathrm{P}>$ 0,05). A gema em nível de ovário apresentou, em valores absolutos, coloração amarela mais intensa que as gemas dos ovos.

Estudos anteriores mostraram que o extrato de urucum acentuava a coloração amarela da gema dos ovos de galinhas (SILVA et al., 2000) e, mais recentemente, da gema dos ovos de codornas (MELO et al., 2003), entretanto, pela primeira vez foi demonstrado que o resíduo da semente de urucum, obtido após a extração da bixina tendo o óleo de soja como solvente, também pode ser usado com a mesma finalidade, com a vantagem de ser mais barato que o extrato oleoso de urucum.

$\mathrm{Na}$ Tabela 5 são mostrados os resultados da avaliação dos pesos e das porcentagens do trato gastrointestinal, pâncreas e fígado. Os pesos do pâncreas $\left(\mathrm{Y}=4,43600-0,120750 \mathrm{X} ; \mathrm{r}^{2}=0,94\right)$ e fígado $(\mathrm{Y}=38,0467-$ $\left.0,666000 \mathrm{X} ; \mathrm{r}^{2}=0,83\right)$ diminuíram linearmente $(\mathrm{P}<0,05)$ à medida que o RSU passou de 4 para $12 \%$ na ração.

TABELA 5 - Pesos e porcentagens do trato gastrointestinal (TGI), pâncreas e fígado em função da ração à base de milho e de farelo de soja (M+FS) e das rações contendo $40 \%$ de sorgo suplementada com o resíduo da semente de urucum (RSU).

\begin{tabular}{lcccccc}
\hline \multicolumn{1}{c}{ RSU (\%) } & TGI (g) & TGI (\%) & Pâncreas (g) & Pâncreas (\%) & Fígado (g) & Fígado (\%) \\
\hline Controle (M+FS) & 161,186 & 2,152 & 3,180 & 0,044 & $45,004^{\mathrm{a}}$ & 0,598 \\
40\%Sorgo+0\%RSU & 165,688 & 2,340 & 3,532 & 0,050 & $38,112^{\mathrm{ab}}$ & 0,537 \\
40\%Sorgo+4\%RSU & 149,946 & 2,000 & 4,024 & 0,054 & $36,090^{\mathrm{ab}}$ & 0,483 \\
$40 \%$ Sorgo+8\%RSU & 141,768 & 1,907 & 3,328 & 0,042 & $31,304^{\mathrm{ab}}$ & 0,422 \\
$40 \%$ Sorgo+12\%RSU & 154,598 & 2,077 & 3,058 & 0,042 & $30,762^{\mathrm{ab}}$ & 0,415 \\
\hline ANOVA & & & & & & \\
\hline Tratamentos & $\mathrm{ns}$ & $\mathrm{ns}$ & $*$ & $\mathrm{~ns}$ & $*$ & $\mathrm{~ns}$ \\
RSU & $\mathrm{ns}$ & $\mathrm{ns}$ & $\mathrm{L}^{*}$ & $\mathrm{~ns}$ & $\mathrm{~L} *$ & $\mathrm{~ns}$ \\
\hline $\mathrm{CV}(\%)^{1}$ & 15,87 & 17,99 & 16,97 & 18,83 & 10,29 & 22,32 \\
\hline
\end{tabular}

$\overline{a, b, c}$ Médias seguidas de letras distintas são diferentes pelo teste SNK $(\mathrm{P}<0,05)$.

${ }^{1}$ Efeitos linear $(\mathrm{L})$, em que: $*(\mathrm{P}<0,05)$.

Ns = não-significativo 


\section{CONCLUSÕES}

O resíduo da semente de urucum melhora a pigmentação da gema dos ovos de galinhas poedeiras alimentadas com altos níveis de sorgo na ração. Este subproduto pode ser incluído em até $12 \%$ na ração.

\section{AGRADECIMENTOS}

Ao Banco do Nordeste do Brasil, pelo apoio financeiro ao projeto.

À empresa Guaraves Alimentos de Guarabira-PB, especialmente, a Ivanildo Coutinho, pela doação do resíduo de urucum.

\section{REFERÊNCIAS BIBLIOGRÁFICAS}

ARRAYA, H. H.; MURILLO, M. R.; VARGAS, E. G. Composicion y empleo del achiote (B. orellana L.) en raciones para gallinas ponedoras, para la pigmentacion de la yema del huevo. Agronomica Costariquense, São José da Costa Rica, v. 1, n. 2, p. 143-150, 1977.

CAMPOS, J. Efeito do urucum na cor da gema de ovos. Revista Ceres, Viçosa, v. 9, n. 53, p. 349-353, 1955.

MELO, D. A.; SILVA, J. H. V.; ROCHA, M. R. F. Níveis de substituição do milho pelo sorgo e uso do extrato oleoso de bixina como corante da gema dos ovos de codornas. In: REUNIÃO ANUAL DA SOCIEDADE BRASILEIRA DE ZOOTECNIA, 40., 2003, Santa Maria, RS. Anais... Santa Maria: SBZ, 2003. CD-ROM.

MIYADA, V. S.; UTIYAMA, C. E.; FIGUEIREDO, A. N. Utilização do resíduo de sementes processadas de urucum (B. orellana L.) na alimentação de suínos em crescimento. In: REUNIÃO ANUAL DA SOCIEDADE BRASILEIRA DE
ZOOTECNIA, 39., 2002, Recife, PE. Anais... Recife: SBZ, 2002. CD-ROM.

PEREIRA, A. V.; ARIKI, J.; KISHIBE, R.; LODDI, M. M. Deposição de pigmentos em frangos de corte alimentados com ração à base de sorgo e bixina. Revista Brasileira de Ciência Avícola, Campinas, n. 3, p. 33, 2001. Suplemento.

ROSTAGNO, H. S.; ALBINO, L. F. T.; DONZELE, J. L. Tabelas brasileiras de exigências nutricionais para aves e suínos: composição de alimentos e exigências nutricionais. Viçosa: UFV, 2000. 141 p.

SQUIBB, R. L.; GUZMAN, M.; SCRIMSHAW, N. S. Carotene and riboflavin retention and serum vitamin levels in vitamin A depleted rats fed four forage meals, achiote meal and African palm oil. Turrialba, Cidade do México, v. 3, p. 91-93, 1953.

SILVA, J. H. V.; SILVA, E. L.; JORDÃO FILHO, J. Efeitos da inclusão do resíduo da semente de urucum (bixa orellana 1.) na dieta para frangos de corte: desempenho e características de carcaça. Revista Brasileira de Zootecnia, Viçosa, v. 34, n. 5, p. 1606-1613, 2005.

SILVA, J. H. V.; ALBINO, L. F. T.; GODÓI, M. J. S. Efeito do extrato de urucum na pigmentação da gema dos ovos. Revista Brasileira de Zootecnia, Viçosa, v. 29, n. 5, p. 14351439, 2000.

UNIVERSIDADE FEDERAL DE VIÇOSA. Central de processamento de dados. SAEG - Sistema para análise estatística e genética. Viçosa, 1983.59 p. 